\title{
Articulações para implementação da Lei 11.769/08 em Aracaju/SE
}

\section{Articulations for the implementation of Law 11.769/08 in Aracaju/SE}

DOI: $10.46814 /$ lajdv3n2-035

Recebimento dos originais: 23/12/2020

Aceitação para publicação: 26/02/2021

Kadja Emanuelle Araujo Santos

Licenciada em Música

Universidade Federal de Sergipe

Endereço: Rua Boquim 313. Aracaju/SE

E-mail: kadjaemanuelle@ hotmail.com

\section{Mateus Tayslan Andrade de Carvalho}

Graduando em Licenciatura em Música

Universidade Federal de Sergipe

Endereço: Rua professor Damião teles de menezes, Aracaju/SE

E-mail: mateustayslan@hotmail.com

\section{Thiago de Sá Oliveira}

Licenciado em Música

Universidade Federal de Sergipe

Endereço: Rua Amazonas, 532. Aracaju/SE

E-mail: thiagodes1@hotmail.com

\section{RESUMO}

O presente trabalho trata da implementação da Lei 11.769/2008, a qual traz a obrigatoriedade da Música para o contexto das escolas de Educação Básica. O objetivo é de relatar as articulações ocorridas no campo acadêmico, os desdobramentos dos concursos e processos seletivos realizados, assim como, as ações de estudantes e egressos do curso de Licenciatura em Música da Universidade Federal de Sergipe, para que ocorra a abertura do campo de trabalho visando a futura atuação dos profissionais que concluíram ou vão concluir a Licenciatura acima citada no Estado de Sergipe. Este artigo apresenta uma revisão de literatura a partir das informações presentes em leis, editais e pesquisas acadêmicas sobre o ensino de música nas escolas de Ensino Fundamental e Médio da cidade de Aracaju.

Palavras chave: Educação Musical, Lei 11.769/08, Educação Básica.

\begin{abstract}
The present work deals with the implementation of Law 11.769/2008, which brings compulsory teaching of music to the context of Basic Education schools. The objective is to report the articulations that took place in the academic field, the unfolding of the competitions and selection processes, as well as the actions of students and graduates of the Music Licensing course at the Sergipe Federal University, so that the opening of the work field occurs, aiming at the future performance of professionals who have concluded or will conclude the above mentioned Licensing course in the State of Sergipe. This article presents a literature review based on information present in laws, edicts and academic research on the teaching of music in elementary and high schools in the city of Aracaju.
\end{abstract}


Key words: Music Education, Law 11.769/08, Basic Education.

\section{INTRODUÇÃO}

No ano de 2008, durante a administração do presidente Luiz Inácio Lula da Silva, foi publicada a Lei Federal $N^{\circ} 11.769$ que altera o artigo 26 da Lei de Diretrizes e Bases da Educação (LDB), $N^{\circ}$ 9.394/1996. Segundo o parágrafo 6, do art. 26: “A música deverá ser conteúdo obrigatório, mas não exclusivo, do componente curricular de que trata o $§ 2^{\circ}$ deste artigo.” (BRASIL, 1996, art. 26, § 6). Os sistemas de ensino tiveram três anos para se adaptarem às exigências estabelecidas para sua implementação, entretanto, o percebido em Sergipe é que a referida Lei é pouco conhecida e não está sendo cumprida em algumas escolas. (SANTOS, 2013, p.58; HARDER et al., 2010, p.1773)

Além da Lei Federal citada acima, o Artigo 222 da Constituição do Estado de Sergipe e o Artigo 309 da Lei Orgânica do Município de Aracaju também estão sendo ignorados na capital do Estado. Ainda no mesmo artigo da Constituição Estadual: “O ensino religioso e o de música, de matrícula facultativa, constituirão disciplina dos horários normais das escolas públicas de ensino fundamental." (SERGIPE, 1989, art. 222, p.73). Já o Artigo 309 da Lei Orgânica, diz que: "O ensino religioso e musical, de matrícula facultativa, constituirá disciplina dos horários normais das escolas municipais". (SERGIPE, 1990, art. 309, p.50).

Apesar da situação descrita nos últimos parágrafos, após a Lei 11.769/08 ser sancionada, ocorreram fatos significativos na área da Educação Musical em Sergipe, dentre os quais se destacam: a implantação do curso de Licenciatura em Música na Universidade Federal de Sergipe, a realização de concursos públicos e processos seletivos para o exercício da profissão, embora estes, em sua maioria, tenham focado o preenchimento temporário das vagas de professor de instrumento especifico no Conservatório local e o ensino em projetos que não caracterizam a inserção real do conteúdo musical nas instituições de ensino municipais e estaduais.

Por meio deste trabalho que tem como objetivo relatar as articulações ocorridas em Sergipe após a publicação da Lei 11.769/2008 aos estudantes, pesquisadores e a todos que fazem a Associação Brasileira de Educação Musical, a fim de que a caminhada rumo a implementação da Música nas escolas seja fortalecida e para que possamos encontrar caminhos que levem a uma maior abertura de campo de trabalho para atuação dos profissionais Licenciados em Música.

\section{PRIMEIRAS ARTICULAÇÕES: A FORMAÇÃO DOCENTE}

Em 2007, o curso de Licenciatura em Música foi implantado na Universidade Federal de Sergipe (UFS), sendo esta, até os dias atuais, a única instituição no Estado a ofertar a Graduação nesta área. Tal fato, ante a publicação da Lei 11.769/2008 foi de suma importância, pois o Estado de Sergipe 
possuía um pequeno número de licenciados neste campo de atuação. De modo geral, a grande maioria dos profissionais que ensinavam música em Aracaju eram músicos populares ou com formação técnica em algum instrumento, profissionais que tinham formação específica em outras áreas e que possuíam algum conhecimento musical, bacharéis em instrumentos específicos e licenciados em Música formados em outros Estados.

De acordo com o Catálogo de Cursos da UFS (2011):

O Curso de Licenciatura em Música da UFS tem como principal objetivo a formação de profissionais para atuar na área da educação, nos ensinos fundamental e médio, nas escolas especializadas e demais contextos de ensino e aprendizagem. (UFS, 2011, p.86)

Com este intuito, o curso vem desenvolvendo ações de ensino, extensão e pesquisa através dos trabalhos desenvolvidos pelo Grupo de Pesquisa Manifestações Musicais de Sergipe e o Grupo de Estudos de Psicologia e História da Música. O curso organiza anualmente eventos acadêmicos, dentre os quais se destacam o Simpósio Sergipano de Pesquisa e Ensino em Música - SISPEM e o Recital dos Alunos de Música da UFS - RAMU. Relacionado ao ensino da disciplina, participa do Programa Institucional de Bolsa de Iniciação à Docência (PIBID) da CAPES e do Programa de Consolidação das Licenciaturas - Prodocência.

As ações do PIBID/Música da UFS e as atividades da disciplina de Estágio Supervisionado contribuem para que aulas de música aconteçam em escolas públicas e particulares de Sergipe, sendo este o primeiro contato de muitas escolas com profissionais e estudantes desta área.

Em 2009, catorze alunos da primeira turma do curso estagiaram em escolas municipais em turmas do $1^{\circ}$ ao $5^{\circ}$ ano do Ensino Fundamental durante um semestre. No ano de 2010, dez estagiários atuaram no mesmo ciclo do Ensino Fundamental e treze atuaram em escolas estaduais, em turmas de $6^{\circ}$ ao $9^{\circ}$ ano (HARDER et al., 2010). Durante o mesmo ano, as atividades do Programa de Iniciação à Docência em Música da Universidade Federal de Sergipe foram iniciadas sob a coordenação da Prof. ${ }^{a}$ Dr. ${ }^{a}$ Rejane Harder. Este programa ficou conhecido entre os alunos como PIBID I. Na pesquisa realizada por Harder e colaboradores, apresentada no XIX Congresso Nacional da Associação Brasileira de Educação Musical, os autores afirmaram que:

O curso de Licenciatura foi ainda contemplado neste ano de 2010 com vinte bolsas do Programa Institucional de Bolsas de Iniciação à Docência-PIBID, oferecida pela CAPES. Dessa forma vinte bolsistas iniciaram sua atuação em escolas estaduais de Aracaju em turmas do $6^{\circ}$ ao $9^{\circ}$ anos. Temos então trinta e três alunos do curso de Licenciatura em Música da UFS ministrando a disciplina "música" em escolas estaduais do município de Aracaju, enquanto dez estagiários estão atuando na Rede Municipal de Ensino, totalizando quarenta e três alunos do curso de Licenciatura em Música da UFS atuando em escolas do sistema público de ensino de Aracaju. Esta é uma experiência pioneira no Estado de Sergipe. (HARDER et al., 2010, p. 1773) 
Em 2012 iniciou-se o PIBID II sob a coordenação da Prof. ${ }^{a}$ Dr. ${ }^{a}$ Mackely Ribeiro Borges e da Prof. ${ }^{a}$ Dr. ${ }^{a}$ Rejane Harder, composto por trinta bolsistas e dois estudantes voluntários, sendo que cinco participantes eram remanescentes do PIBID I (SANTOS, 2013, p.58; HARDER et al., 2010, p.173).

Em 2013, com a oferta de 50 bolsas, nove escolas da rede pública estadual foram contempladas pelo programa. Já no presente ano, a Prof. ${ }^{a}$ Dr. ${ }^{a}$ Priscila Garcia, o Prof. Dr. Eduardo Garcia e a Prof. ${ }^{a}$ Dr. ${ }^{a}$ Rejane Harder, passaram a coordenar as atividades do programa, que conta com 60 bolsas. Com este número de oferta o PIBID/Música de Sergipe tornou-se o PIBID com maior número de bolsistas no país.

No mesmo ano de início das atividades do PIBID/Música, em 2010, aconteceu o I Simpósio Sergipano de Pesquisa e Ensino em Música- SISPEM, idealizado pelo Núcleo de Música (NMU) a partir da demanda local por um espaço acadêmico voltado para discussões relacionadas à pesquisa e ensino do conteúdo musical. Desde então, o evento vem ocorrendo anualmente e ao longo dos seus cinco anos promoveu cursos, workshops e palestras, além de ter se tornado um importante espaço para divulgação das produções científicas realizadas por estudantes e profissionais da área.

Em seu primeiro ano de realização teve como temática: As reflexões em torno dos desafios e perspectivas para o ensino da música em Sergipe, levando-se em consideração a nova realidade estabelecida pela lei 11.769/2008. O evento contou com a participação do Prof. Dr. Sérgio Figueiredo como ministrante de workshops, cursos, palestra e participante da mesa redonda: “A implementação da música como componente curricular obrigatório do Ensino Básico no Brasil”, em que estiveram presentes representantes da Secretaria de Estado da Educação de Sergipe e a Prof. ${ }^{a}$ Dr. ${ }^{a}$ Rejane Harder.

No que se refere à formação musical de pedagogos, o curso de Pedagogia da Universidade Federal de Sergipe não tem em seu currículo nenhuma disciplina específica relacionada à educação musical. Há em sua grade a disciplina obrigatória Arte/Educação que também é disciplina optativa para o curso de Música e outros cursos de licenciatura na área de Ciências Humanas.

Em 2013, a Faculdade Pio Décimo ofertou o Curso de pós-graduação Lato Sensu em Música: Pedagogia Musical, destinado a graduados em Música, Musicoterapia, Arte Educação, Pedagogia e Artes Cênicas. Localizada em Aracaju, a instituição é a pioneira na oferta do curso de Especialização em Música no Estado. A primeira turma, composta por $60 \%$ de egressos do curso de Licenciatura da UFS, concluirá o curso no segundo semestre de 2014 e para este mesmo ano já foram ofertados novos cursos de especialização relacionados a música: Pedagogia do Canto, Pedagogia Musical e Musicoterapia. 


\section{CONCURSOS PÚBLICOS}

\subsection{REDE MUNICIPAL DE ARACAJU}

No ano de 2011, a Prefeitura Municipal de Aracaju e a FUNCAB (Fundação Professor Carlos Augusto Bittencourt), abriram um Concurso Público para o provimento de 152 vagas visando os cargos de Professor de Nível Superior da Educação Infantil e do primeiro ao quinto ano do Ensino Fundamental, e, Cadastro de Reserva para o quadro de Professor de Nível Superior das demais áreas do currículo do Ensino Fundamental da Secretária Municipal de Educação de Aracaju/SE, dentre as quais está inclusa no edital a disciplina Música. Setenta e oito pessoas foram aprovadas para a vaga de Professor de Música, com salário mensal de 1.498 reais e 48 centavos, entretanto, até o presente momento ninguém foi convocado a assumir o cargo.

Após consulta ao Sindicato dos Profissionais do Ensino do Município de Aracaju (Sindipema), no corrente ano, constatou-se que nenhuma das escolas públicas da prefeitura tem em seu quadro de funcionários efetivos professores da disciplina em questão. O que acaba por tornar o concurso pra Cadastro de Reserva algo "estranho", visto que não há profissionais atuantes nesse campo. Tal constatação já havia sido feita também por Santos (2013), segundo a autora:

no caso da Rede Pública Municipal de Aracaju/SE, observa-se que ainda não há de fato a implementação da Lei 11.769/2008, apesar de algumas unidades já possuírem projetos que incluam experiências com a música e de alguns gestores considerarem que suas escolas já possuam o ensino de música, através da entoação de músicas na hora do recreio ou nas comemorações de datas cívicas e outras festividades. Entretanto, já são encontrados alguns avanços para a mudança desse quadro, como o concurso para professor de música da Secretaria Municipal de Educação (SEMED) realizado no final de 2011, embora até o ano de 2012 nenhum candidato aprovado tenha sido convocado para atuar nas escolas. (SANTOS, 2013, p.61)

Neste mesmo período, a Secretária de Educação do Município foi procurada a fim de que concedessem uma entrevista para a pesquisa do trabalho de conclusão de curso intitulado "Caminhos para a implementação da Lei 11.6769/2008 na rede pública municipal de ensino de Aracaju/SE” de Cássia Tawana Silveira Santos. A pesquisa foi realizada em 43 escolas da rede municipal de Aracaju, porém, não foi possível o encontro com a secretária Prof. a Márcia Valéria Lira Santana, sendo a ação direcionada à Diretoria de Ensino, representada pelo Professor Dênison Sant'Anna. Conforme relato da autora:

Ao ser interrogado sobre o conhecimento da Lei 11.769/2008, o Diretor de Ensino afirmou que a desconhecia. Mesmo sem conhecê-la, ele informou que a Secretaria Municipal de Educação já está planejando incluir o ensino de música nas suas escolas e convocar alguns dos candidatos que foram aprovados para o cargo de professor de Música da SEMED. Nessa oportunidade também foi solicitada uma entrevista, contudo o Diretor informou que teria sido convocado para uma reunião e solicitou gentilmente o roteiro desta para que pudesse respondê-la a punho, deixando marcado o dia da possível entrega. Infelizmente a pesquisa foi concluída sem os 
resultados dessa entrevista, pois esta não foi entregue na data acertada e apesar de ter sido remarcado outro dia para entrega não foi possível esperar. (SANTOS, 2013, p. 46)

Atualmente, na rede municipal de Aracaju acontecem os seguintes projetos: Mais Educação; o Fascínio do Mundo através da Leitura e Escrita; Coral de Inclusão Mãos Falantes e Orquestra Sinfônica Cidade de Aracaju.

\subsection{REDE ESTADUAL}

Em 2010, a Secretaria de Estado da Educação de Sergipe realizou um processo seletivo simplificado visando a contratação de professores da Educação Básica de diversas disciplinas para atuação em Aracaju e outros municípios do Estado. Neste edital foram disponibilizadas 17 vagas para área de Música, sendo que o exercício das atividades destes profissionais ficaria a cargo da Diretoria de Educação de Aracaju (DEA), órgão responsável pelo comando das escolas desta cidade.

As vagas foram distribuídas entre disciplinas teóricas, de instrumentos específicos e informática. Em um dos níveis, a formação exigida para que os aprovados assumissem o cargo era possuir o Certificado de Conclusão do Nível Técnico ou apresentar uma comprovação de que estivessem cursando o $5^{\circ}$ período da Licenciatura em Música, tendo concluído pelo menos $50 \%$ dos créditos exigidos para completar o curso. Todos os contratados da área de Música foram encaminhados para lecionar no Conservatório de Música de Sergipe. (SECRETARIA DE ESTADO DA ADMINISTRAÇÃO, 2010)

No ano de 2012, o Governo do Estado de Sergipe e a Fundação Professor Carlos Augusto Bittencourt (FUNCAB), abriram um Concurso Público para o provimento de 65 vagas visando o cargo de Professor da Educação Básica da Disciplina Artes para diversas regiões de Estado. Sobre este concurso vale ressaltar que o requisito de escolaridade exigido para que os aprovados assumissem as vagas disponibilizadas era o diploma em curso superior de licenciatura plena em Artes (Dança, Música, Teatro, Cinema, Desenho ou Arte Educação). (DIÁRIO OFICIAL DO ESTADO DE SERGIPE, 2012, p.2)

Após o lançamento do edital, o Diretório Acadêmico do curso de Licenciatura em Música da UFS (DAM), enviou um documento solicitando a retificação do edital sobre os requisitos para investidura do cargo de professor de Artes. Em resposta ao DAM, a Secretaria Estadual de Planejamento, Orçamento e Gestão (SEPLAG) indeferiu o pedido argumentando que:

O trabalho da comissão organizadora, no que tange ao componente curricular de artes, ocorrem no sentido de permitir ampla participação dos profissionais que laboram com tais conteúdos sem preterir ou prestigiar uma área específica de formação. Tal linha de conduta tem o intuito de selecionar profissionais da educação que seja capazes de lecionar as linguagens relacionadas às artes de forma generalista, pois, repise-se, não se almeja como objetivo principal a seleção 
de professores especialistas. (SECRETARIA ESTADUAL DE PLANEJAMENTO, ORÇAMENTO E GESTÃO. 2012, p.1).

Neste concurso, 20 estudantes e egressos do curso de Licenciatura em Música foram aprovados. Destes, 05 foram convocados, estando 02 em atuação no Conservatório de Música de Sergipe e 03 em escolas de Ensino Básico, lecionando também outras disciplinas para conseguirem complementar suas cargas horárias curriculares.

Em 2013, a SEPLAG realizou dois processos seletivos visando a contratação temporária e Cadastro de Reserva de professores de diversas áreas, incluindo Música, para desenvolver atividades nas unidades de ensino do Estado que oferecem Educação Profissional. Foram abertas 31 vagas para a formação do quadro de docentes do Conservatório de Música de Sergipe (cursos Técnico e Básico). O requisito para o cargo era o Nível Superior em Música, análise do currículo dos candidatos e aprovação numa prova prática. (SECRETARIA DE ESTADO DO PLANEJAMENTO, ORÇAMENTO E GESTÃO, 2013).

\subsection{OUTROS PROCESSOS SELETIVOS}

Nos últimos anos, o Serviço Social do Comércio de Sergipe (Sesc-Sergipe), realizou processos seletivos que abriram, minimamente, o campo de trabalho em Aracaju. No processo seletivo $\mathrm{n}^{\circ}$ 001/2010, o requisito para o cargo de Professor de Música era possuir Nível Superior em qualquer área (SERVIÇO SOCIAL DO COMÉRCIO, 2010a, p. 3). Já no edital $\mathrm{n}^{\circ}$ 002/2010, o requisito para um cargo similar, era possuir o Nível Superior e conhecimento em Regência de Canto Coral (SERVIÇO SOCIAL DO COMÉRCIO, 2010b, p. 2).

Em 2012, o mesmo órgão abriu um novo processo seletivo visando a atuação de um profissional na cidade de Indiaroba, município de Sergipe. O requisito para o cargo era a conclusão do Ensino Médio e possuir experiência em canto coral, flauta doce ou outros instrumentos musicais, mediante prova objetiva, comprovação de capacitação e experiência, entrevistas e provas práticas. (SERVIÇO SOCIAL DO COMÉRCIO, 2012b, p.2).

Ainda em 2012 e em meados de 2013, mais dois editais foram lançados para o cargo de Professor de Música. O requisito apresentado no edital nº 012/2012 era que o candidato possuísse Nível Superior completo com experiência mínima de um ano em canto e instrumento (flauta doce e/ou violino) com comprovação (SERVIÇO SOCIAL DO COMÉRCIO, 2012, p. 2). Já no edital 006/2013, o requisito solicitado era que o candidato tivesse Nível Superior em qualquer área, no mínimo seis meses de atuação na docência de aulas de música, mediante comprovação de experiência e entrevista. (SERVIÇO SOCIAL DO COMÉRCIO, 2013, p. 2). 
Embora o SESC tenha realizado todos esses processos, vale frisar que o órgão não tem ligação com as escolas da rede pública estadual e municipal.

\section{ARTICULAÇÕES CIVIS}

Tendo em vista a situação exposta ao longo do texto, um grupo de estudantes e recém-formados em Música da Universidade Federal de Sergipe, vem tentando entrar em contato com órgãos e instituições responsáveis, tais como Sindicatos, Secretarias de Educação e o Ministério Público do Estado de Sergipe (MPE), a fim de dialogar sobre a Educação Musical na Rede Básica de Ensino no Estado. Entretanto, nas conversas realizadas até o momento o que se percebe é que não existe uma previsão para a abertura de novos editais e as Secretarias não tem pretensão alguma de contratar os profissionais recém-formados para ministrar aulas em suas redes de Ensino.

\section{CONSIDERAÇÕES}

Diante do breve panorama descrito e das Leis apresentadas neste trabalho (Lei 11.679/08, Artigo 222 da Constituição do Estado de Sergipe e Artigo 309 da Lei Orgânica do Município de Aracaju), percebe-se a necessidade de colocar em discussão os caminhos para que a música seja inserida nas escolas.

Reconhecemos o trabalho de formação realizado pelas instituições escolares, no entanto, é preciso que uma ação conjunta entre estudantes, professores e órgãos representativos seja realizada para que futuramente contratações e editais de concursos públicos para professor especifico aconteçam, garantindo assim que a Música esteja presente em todas as escolas como preveem as Leis.

É preciso também repensarmos e discutirmos sobre a Educação Musical em Sergipe, tomando como exemplo as ações aplicadas em outros Estados e encontrando soluções para os problemas observados até o momento. Deste modo acreditamos que a disciplina Música será fortalecida e contribuirá positivamente para a formação de pessoas críticas, sensíveis e reflexivas a partir do momento em que seja realmente inclusa na Educação Básica. 


\section{REFERÊNCIAS}

BRASIL. Lei 9.394/96, de 20 de dezembro de 1996. Estabelece as diretrizes e bases da educação nacional. Diário Oficial da União, Brasília, DF, 1996. Disponível em:

<http://www.planalto.gov.br/ccivil_03/leis/19394.htm> Acesso em: 02 ago 2014.

Lei 11.769, de 18 de agosto de 2008. Altera a Lei ${ }^{\circ}$ 9.394/96, de 20 de dezembro de

1996, Lei de Diretrizes e Bases da Educação, para dispor sobre a obrigatoriedade do ensino da música na educação básica. Diário Oficial de União, Brasília, DF, 2008. Disponível em: <http://www.planalto.gov.br/ccivil_03/_Ato2007-2010/2008/lei/L11769.htm> Acesso em: 02 ago 2014.

CATÁlOGO DE CURSOS UFS. A música que vem da sala de aula. Disponível em: <http://www2.ccv.ufs.br/ccv/concursos/pss2012/files/Catalogo2011.pdf> Acesso em 06 ago 2014

DIÁRIO OFICIAL DO ESTADO DE SERGIPE. Concurso público $n^{o}$ 01/2012. Edital nº1, de 27 de Janeiro de 2012. Aracaju: SEGRASE, 30 jan. 2012. Disponível em: <https://segrase.se.gov.br/ler_diarios.htm?edi_id=45\#> Acesso em: 16 ago. 2014

HARDER, Rejane. et al. Panorama do ensino de música nas escolas de Ensino Fundamental e Médio da cidade de Aracaju, Sergipe. XIX CONGRESSO NACIONAL DA ASSOCIAÇÃO BRASILEIRA DE EDUCAÇÃO MUSICAL, Goiânia, 2010. Anais do XIX Congresso Nacional da Associação Brasileira de Educação Musical. Goiânia: UFG, 2010. Disponível em: <http://www.abemeducacaomusical.org.br/Masters/anais2010/Anais_abem_2010.pdf> Acesso em: 10 ago 2014.

PREFEITURA MUNICIPAL DE ARACAJU. Edital $n^{\circ}$ 01/2011 de 19 de Outubro de 2011. Disponível em: <http://www.aracaju.se.gov.br/userfiles/concursos/ed_n1_2011_magisterio.pdf>. Acesso em 16 ago 2014.

SANTOS, Cássia Tawana Silveira dos. Caminhos para a implementação da Lei 11.6769/2008 na rede pública municipal de ensino de Aracaju/SE. Monografia (Licenciatura em Música) - Núcleo de Música. Universidade Federal de Sergipe, São Cristóvão, 2013.

SECRETARIA DE ESTADO DA ADMINISTRAÇÃO. Edital de Processo Seletivo Simplificado $n^{o}$. 003/2010. $2010 . \quad$ Disponível em: <http://www.seed.se.gov.br/arquivos/processo_seletivo_simplificado_edital.pdf> Acesso em: 13 set 2014

SECRETARIA DE ESTADO DO PLANEJAMENTO, ORÇAMENTO E GESTÃO. Resposta à solicitação de retificação de edital do concurso público. Ofício $\mathrm{N}^{\circ}$ 093, ref. SEPLAG/ASTEC. Aracaju, 2012.

. Edital de Processo Seletivo Simplificado $n^{o}$. 01/2013. 2013. Disponível em: <http://www.seplag.se.gov.br/images/CONCURSO_ANDAMENTO/SEED/PSS_01-2013/01__Edital_de_Abertura_PSS_n\%C2\%BA_01-2013.pdf> Acesso em: 13 set 2014.

SERGIPE. Constituição do Estado de Sergipe. Aracaju, 1989. Disponível em <http://www.al.se.gov.br/cese/constituicao_do_estado_de_sergipe_2007.pdf> Acesso em: 05 ago 2014. 
Lei Orgânica do Município de Aracaju. Aracaju, 1990. Disponível em: <http://www.dhnet.org.br/direitos/municipais/a_pdf/lei_organica_se_aracaju.pdf> Acesso em: 05 ago 2014.

SERVIÇO SOCIAL DO COMÉRCIO - SESC. Edital de Processo Seletivo $n^{o}$ 001/2010, para provimento de vagas, bem como para formação de cadastro de reserva para diversas áreas nos níveis Fundamental, Médio e Superior. 2010a. Disponível em: <http://www.advise.net.br/editais/sesc_se_edital_ret_2010.03.10.pdf> Acesso em: 14 set 2014

Edital de Processo Seletivo $n^{\circ}$ 002/2010, para provimento de vagas, bem como para formação de cadastro de reserva para diversas áreas nos níveis Médio e Superior. 2010b. Disponível em: <http://www2.sesc-se.com.br/Edital\%20\%20Processo\%20Seletivo\%20Final.pdf> Acesso em: 14 set 2014

. Descritivo do Processo Seletivo para Composição de Cadastro Reserva $n^{\circ}$ 002/2011. 2011. Disponível em: <http://www2.sesc-se.com.br/editais/DESCRITIVODOPROCESSOSELETIVO.pdf $>$. Acesso em: 14 set 2014.

Descritivo do Processo Seletivo para Composição de Cadastro Reserva, no 012/2012. 2012. Disponível em <http://www.sesc-se.com.br/editais/descritivo012_2012.pdf>. Acesso em: 14 set 2014.

Descritivo do Processo Seletivo para Contratação de Professor de Música para o SESC Ler Indiaroba $-N^{\circ}$ 003/2012. 2012. Disponível em: <http://www.sesc-se.com.br/editais/descritivo-doprocesso-seletivo-003.2012-indiaroba.pdf>. Acesso em: 14 set 2014.

. Descritivo do Processo Seletivo para Composição de Cadastro Reserva, $n^{\circ}$ 006/2013. 2013. Disponível em <http://www.sesc-se.com.br/editais/DESCRITIVO_006_2013.pdf〉. Acesso em: 14 se 